\title{
Potencialidades do uso de uma trilha ecológica educativa para a percepção e problematização socioambiental
}

\section{Potentialities in the use of an ecological educational trail for social environmental perception and problematization.}

\author{
${ }^{1}$ Cilene de Souza Silva Freitas cilenebio@gmail.com \\ ${ }^{2}$ Eliene dos Santos Lopes \\ ${ }^{3}$ Benjamin Carvalho Teixeira Pinto
}

\section{RESUMO}

Essa pesquisa tem como objetivo investigar as potencialidades do uso de trilhas ecológicas em atividade de Educação Ambiental. Uma planilha de diagnóstico socioambiental foi utilizada como instrumento para evidenciar a percepção ambiental dos estudantes. Por meio da percepção ambiental foi possível conhecer os problemas socioambientais do cotidiano dos estudantes oportunizando problematizações, diálogos e melhor construção do conhecimento da temática ambiental. A pesquisa revelou que o contato direto com os elementos do meio ambiente contribuiu efetivamente para a construção de conceitos novos e uma relação mais ampla dos diversos aspectos relacionados ao meio ambiente. Além disso, o contato e vivência na trilha do Jequitibá-rosa permitiu o interesse pela descoberta e valorização de temas que muitas vezes são abordados de maneira abstrata em sala de aula.

Palavras-chave:Espaço não formal. Educação ambiental. Ensino de ciências e biologia. Percepção ambiental.

\begin{abstract}
This research aims to investigate the potential of using ecological trails in Environmental Education activities. A socio-environmental diagnostic spreadsheet was used as an instrument to evidence the perception the students' environmental. Through environmental perception, it was possible knowing the socio-environmental problems of the students'daily lives, opportunizing for problematization, dialogues and better construction of knowledge on environmental issues. The research revealed that direct contact with the elements of the environment effectively contributed to the construction of new concepts and a wider relationship of the various aspects related to the environment. In addition, the contact and experience on the Jequitibá-rosa trail allowed the interest in discovering and valuing themes that are oftentimes addressed in an abstract manner in the classroom.
\end{abstract}

Keywords: Non-formal space. Environmental education. Teaching science and biology. Environmental perception.

\footnotetext{
1 Mestre em Educação em Ciências e Matemática, Área de Concentração em Ensino e Aprendizagem em Ciências e Matemática, pela Universidade Federal Rural do Rio de Janeiro.

2 Atuando nas áreas de Ensino de Ciências e Biologia, Educação Ambiental e Educação em Espaços Não Formais. Universidade Federal Rural do Rio de Janeiro.

3 Doutor em Ciências Biológicas. Universidade Federal Rural do Rio de Janeiro.
} 


\section{INTRODUÇÃO}

A "percepção" é a manifestação de um processo individual que permite a formação de sistemas simbólicos e representações mentais do mundo. Ela é a consciência e assimilação do meio ambiente, por meio dos sentidos (OLIVEIRA, 2009). O ser humano age de acordo com a sua percepção. Dollfus (1991) afirma que a percepção do espaço real vem somar-se a elementos irracionais, míticos e religiosos. Nessa linha de pensamento, acredita-se que cada sujeito interpreta o mundo exterior de forma particular. Situações comuns a várias pessoas são únicas para cada observador, já que estas se combinam às experiências anteriores de quem observa.

Para Alves (1995) a percepção ocorre no campo da interação com o meio ambiente e no diálogo entre diferentes áreas. A qualidade dessa interação e desse diálogo contribui para o desenvolvimento da percepção ambiental. Assim, é através da interação com o meio que o indivíduo estabelece e constrói identidades. Essa interação pode ser iniciada a partir do conhecimento da estrutura e do funcionamento do meio, por intermédio de vivências, pesquisa etc. Além disso, é pelo diálogo que se dá o auto reconhecimento e o reconhecimento do outro, em um encontro do qual saímos modificados e, ao mesmo tempo, com um contorno individual mais nítido. Trata-se, assim, de um confronto criativo que aproxima e, ao mesmo tempo, enriquece as diferenças.

Convém enfatizar que para análise dos resultados sobre o conhecimento e da percepção ambiental, consta-se a necessidade de considerar a percepção como sendo única de cada indivíduo, uma vez que requer o contato do indivíduo com o ambiente nas várias etapas da vida, nos vários momentos de aprendizagem, dependente de fatores sociais e culturais. Conforme estudo realizado por Oliveira (2009), o contato com o mundo exterior se dá através do nosso corpo, dos nossos sentidos, de forma seletiva e instantânea, que por meio dos estímulos sensoriais proporcionam as sensações que obrigatoriamente passam pelos nossos filtros sociais, culturais, tornando-se, assim, percepções. Deste modo, a percepção é necessariamente individual, o que é percebido por um indivíduo pode ser imperceptível a outro, ou mostrar-se diferente nas várias pessoas que recebem os mesmos estímulos sensoriais, visto que dependem dos filtros sociais, culturais de cada um. "Os filtros culturais e individuais são produto de interesse, da necessidade e da motivação, são tão importantes, em nossa percepção que muitas vezes determinam nossas de decisões e tomadas de consciência” (OLIVEIRA, 2009, p. 53). Além disso, conforme o esquema de Camillo (2007 apud OLIVEIRA, 2009), as atividades perceptivas são atividades mentais intermediárias que ocorrem entre a percepção e a cognição (Fig.1).

\section{Figura 1. Esquema do processo perceptivo cognitivo.}

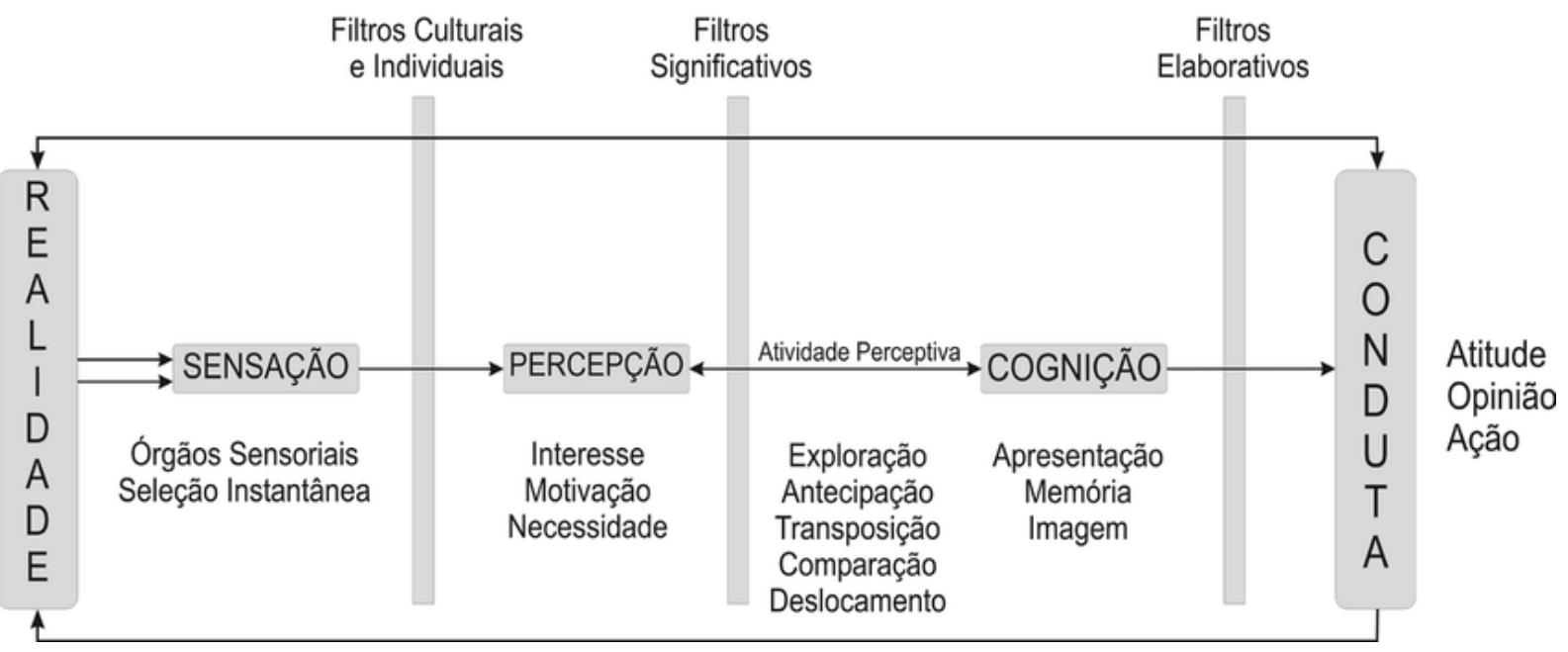

Fonte: CAMILLO, 2007 apud OLIVEIRA, 2009.

Um marco histórico no estudo da percepção ambiental, de acordo com a pesquisadora Lívia Oliveira (2001 apud MARIN, 2008, p. 209) foi a obra publicada em 1977 - “Guidelines for field studies in environmental 
perception”. Outro estudo relevante foi publicado por Del Rio e Oliveira (1999) em que realizaram o primeiro levantamento acerca das pesquisas em percepção ambiental no Brasil, atualizado recentemente por Alves (2016) que realizou o estado da arte dos estudos da percepção ambiental no Brasil do período entre 2008 e 2015.

Conforme Siebenhuener (1999) apud Romeiro (2010) a constituição biológica e psicológica do ser humano moderno foi formada há cerca de 40.000 anos, bem como seus sentimentos em relação à natureza, quando eram caçadores e coletores. Assim, os sentimentos mais primitivos ou mais relacionados com a natureza foram perdidos ou estão "amortecidos" pelo processo de civilização e por determinado desenvolvimento cultural, mas que podem ser recuperados por meio da Educação Ambiental.

Por essas razões, é essencial a realização de atividades para diagnosticar a percepção ambiental e, assim, abordar temas significativos de interesse e da realidade dos estudantes, a fim de problematiza-los em uma abordagem crítico-reflexiva na Educação Ambiental (LOUREIRO e TORRES, 2014; PINTO e BORGES, 2015; FREITAS et al., 2017; FERREIRA-ALVIM e PINTO, 2017; PINTO e CAMILO, 2020).

Com base nessas premissas, a presente pesquisa tem como objetivo avaliar o dispositivo de uma planilha como instrumento para diagnóstico da percepção ambiental e as potencialidades do uso de uma trilha ecológica em atividade de Educação Ambiental.

As trilhas ecológicas são excelentes locais para desenvolver atividades de Educação Ambiental, uma vez que permitem maior contato com elementos da natureza ou elementos construídos/modificados, sensibilizando os estudantes para o tema "meio ambiente". Estudos recentes (MENGHINI, 2005; LECHNER, 2006; MARQUES et al., 2013; PIN e CAMPOS, 2014; ACORDI e PASA, 2014; ROCHA et al., 2016; FREITAS et al., 2016; PIN, 2019) vêm analisando o uso de atividades educativas em trilhas ecológicas como possibilidade de explorar seus elementos em práticas de Educação Ambiental e ensino de Ciências.

\section{CAMINHOS METODOLÓGICOS}

O presente estudo foi realizado com a participação de alunos do ensino fundamental da escola CAIC e alunos do ensino Médio da escola Presidente Dutra, município de Seropédica, RJ.

A proposta da pesquisa foi realizar atividades de percepção ambiental, por meio de uma planilha de diagnóstico socioambiental, em trilhas de uma Unidade de Conservação. Foi escolhida a trilha - Jequitibá-rosa inserida no Parque Natural Municipal do Curió Paracambi (PNMCP), localizada no Rio de Janeiro ${ }^{4}$.

A atividade de percepção ambiental na trilha com uso da planilha diagnóstica se desenvolveu em dois percursos: No percurso de ida até o marco final do trecho da trilha e no percurso de retorno. O ponto de partida iniciou-se próximo a um açude e o ponto final foi em um mirante da trilha na Pedra do G4. O percurso percorrido de ida e retorno teve duração média de três horas em cada visita. O percurso de ida teve como objetivo percorrer a trilha sem nenhuma interferência, onde os estudantes pudessem observar o ambiente e, também, preenchessem a planilha de diagnóstico socioambiental no percurso da trilha, a fim de obter a percepção ambiental de cada aluno. O trajeto de retorno teve como objetivo percorrer a trilha e realizar paradas em quatro pontos - açude, ETA CEDAE, Jequitibá-rosa e Pedra G4 - pré-estabelecidas, para a realização das atividades de problematização e discussões acerca dos aspectos observados e destacados pelos estudantes na planilha de diagnóstico socioambiental ao longo do trajeto de ida na trilha.

4 O PNMCP foi criado pelo Decreto Municipal n ${ }^{\circ}$ 1001, de 29 de janeiro de 2002 e alterado pela Lei Municipal ${ }^{\circ} 921$, de 30 de abril de 2009, fica no município de Paracambi e possui $186,8 \mathrm{~km}^{2}$, localizando-se na região noroeste da Região Metropolitana do Rio de Janeiro. É o segundo maior parque municipal do estado do Rio de Janeiro. Possui 913 hectares de Mata Atlântica remanescente e é um importante corredor ecológico localizando-se zona central do Corredor da Biodiversidade Tinguá-Bocaina. 
A trilha - Jequitibá-rosa - foi escolhida por ser curta e possuir encostas com declividades suaves. Além disso, é uma trilha localizada próxima da Secretaria de Meio Ambiente (SEMADES) de Paracambi, RJ, onde foi possível receber um suporte de segurança dos guardas ambientais. O trecho da trilha possui grande diversidade de vegetação secundária e uma grande variedade de pássaros. Entretanto, são encontrados muitos trechos com perturbação antrópica.

\section{1 Dispositivo da planilha de diagnóstico socioambiental}

A planilha de diagnóstico socioambiental possui dez questões abertas e fechadas e foi desenvolvida com a finalidade de registrar a percepção ambiental dos estudantes ao longo da trilha. Por meio desse instrumento, utilizaram-se três critérios: 1) Análise da observação e da percepção; 2) Utilização de palavras e expressões; 3) Análise do diálogo (Quadro 1).

Quadro 1. Planilha de diagnóstico socioambiental. Questões, objetivos e critério de análise da percepção ambiental ao longo do trajeto na trilha.

\begin{tabular}{|c|c|}
\hline Planilha de diagnóstico socioambiental & \\
\hline Questões & Objetivos \\
\hline $\begin{array}{l}\text { 1.Sons encontrados ao longo da trilha } \\
\text { Espaço para o aluno registrar exemplos observados/ } \\
\text { encontrados na trilha: }\end{array}$ & $\begin{array}{l}\text { Averiguar se os alunos conseguem identificar os } \\
\text { sons encontrados na trilha. }\end{array}$ \\
\hline $\begin{array}{l}\text { 2. Aspectos da água } \\
\text { Espaço para o aluno registrar exemplos observados/ } \\
\text { encontrados na trilha: }\end{array}$ & $\begin{array}{l}\text { Refletir em todo o percurso a importância da } \\
\text { água. Discutir aspectos sobre a poluição e uso } \\
\text { inadequado da água. }\end{array}$ \\
\hline $\begin{array}{l}\text { 3.Aspectos da serapilheira } \\
\text { Espaço para o aluno registrar exemplos observados/ } \\
\text { encontrados na trilha: }\end{array}$ & $\begin{array}{l}\text { Refletir e discutir nos pontos de paradas } \\
\text { aspectos da serrapilheira relacionados aos ciclos } \\
\text { biogeoquímicos, ciclagem dos nutrientes etc. } \\
\text { Problematizar sobre a introdução das espécies } \\
\text { exóticas; tráfico de animais silvestres e } \\
\text { dispersores de sementes. }\end{array}$ \\
\hline $\begin{array}{l}\text { 4.Importância da Unidade de Conservação } \\
\text { Exemplos encontrados na trilha: }\end{array}$ & $\begin{array}{l}\text { Refletir acerca da função do PNMCP como } \\
\text { corredor ecológico possibilitando o fluxo gênico } \\
\text { (EM) e a manutenção da biodiversidade. } \\
\text { A conservação das espécies para a manutenção do } \\
\text { ecossistema. }\end{array}$ \\
\hline
\end{tabular}


5.Ocupação do solo pela vegetação: Açude:

( ) vegetação rasteira

( ) grandes árvores ( ) raízes expostas

( ) apenas grama ( ) solo descoberto

ETA CEDAE:

( ) vegetação rasteira

( ) grandes árvores ( ) raízes expostas

( ) apenas grama ( ) solo descoberto Jequitibá-rosa:

( ) vegetação rasteira

( ) grandes árvores ( ) raízes expostas

( ) apenas grama ( ) solo descoberto

Pedra do G4:

( ) vegetação rasteira

( ) grandes árvores ( ) raízes expostas

( ) apenas grama ( ) solo descoberto

6.Luminosidade nos trechos da trilha: Açude:

( ) intensa ( ) média ( ) pouca

ETA CEDAE:

( ) intensa ( ) média( ) pouca

Jequitibá-rosa:

( ) intensa( ) média( ) pouca

Pedra do G4:

( ) intensa( ) média ( ) pouca

7.Microclima nos trechos da trilha:

Açude:

( ) intensa ( ) média ( ) pouca

ETA CEDAE:

( ) intensa ( ) média ( ) pouca

Jequitibá-rosa:

( ) intensa( ) média ( ) pouca

Pedra do G4:

( ) intensa ( ) média ( ) pouca

8. Grau de umidade da serrapilheira

Açude:

( ) intensa ( ) média ( ) pouca

ETA CEDAE:

( ) intensa ( ) média ( ) pouca

Jequitibá-rosa:

( ) intensa( ) média ( ) pouca

Pedra do G4:

( ) intensa ( ) média ( ) pouca

9. Nível de decomposição da serrapilheira

Açude:

( ) intensa ( ) média ( ) pouca

ETA CEDAE:

( ) intensa ( ) média ( ) pouca

Jequitibá-rosa:

( ) intensa( ) média ( ) pouca

Pedra do G4:

( ) intensa ( ) média ( ) pouca

10. Seres vivos e sua interação com o meio

Espaço para o aluno citar seres vivos e interações

observados/encontrados na trilha:
Analisar a percepção e observação

Analisar a percepção e observação

Analisar a percepção e observação

Analisar a percepção e observação

Analisar a percepção e observação 


\section{2 Análise de dados da pesquisa}

A pesquisa neste trabalho teve caráter qualitativo e se apresenta como um estudo de caso. De acordo com Marconi e Lakatos (2010), por meio da análise qualitativa se investiga e interpreta aspectos mais profundos, descrevendo a complexidade do comportamento humano, analisando mais detalhadamente os hábitos, atitudes, percepções etc.

As atividades de campo foram apoiadas nas teorias construtivistas e sociointeracionistas (BASTOS, 1998; GILL-PÉREZ et al., 2002; VYGOTSKY, 2001) e, assim, a interação foi realizada entre professores das escolas, pesquisadores da Universidade, bolsistas de Iniciação Científica e alunos das escolas nas atividades de exploração, investigação, problematizações e diálogos dos temas abordados.

O projeto de pesquisa foi submetido à Comissão de Ética na Pesquisa da UFRRJ (COMEP), protocolo N $^{\circ}$ 942/17, processo 23083.012222/2017-54, atendendo aos princípios éticos e estando de acordo com a Resolução 466/12, que regulamenta os procedimentos de pesquisa envolvendo seres humanos.

\section{RESULTADOS E DISCUSSÃO}

Participaram das etapas na presente pesquisa, 20 alunos do Curso Normal (Formação de Professores em nível médio) do Colégio Estadual Presidente Dutra e 10 alunos do $9^{\circ}$ ano do Ensino Fundamental do CAIC Paulo Dacorso Filho, instituições escolares localizadas no entorno da Universidade Federal Rural do Rio de Janeiro, campus Seropédica, RJ.

Durante a trilha os estudantes perceberam, sentiram e anotaram suas observações e percepções na planilha de diagnóstico socioambiental. Foram registrados pelos estudantes, por exemplo, o som do vento e da água, o som do vento batendo nas folhas e galhos das árvores, o som da correnteza, seguido dos sons do canto dos pássaros e insetos como grilos e cigarras. Sobre os sons percebidos, destacam-se as expressões abaixo:

Estudante B - Dutra: "Som da correnteza, as folhas se partindo quando pisamos, os galhos balançando, cigarras";

Estudante C - Dutra: "Som de águas e o vento batendo nas árvores, cigarra”;

Estudante E - Dutra: "Barulho do vento balançando as árvores e plantas, barulho da queda da água, da cachoeira, o som dos pássaros e das cigarras”;

Estudante H - Dutra: “O vento batendo nas árvores, os pássaros, o som da água da cachoeira o som dos insetos como: grilos, cigarras, bicho-pau”;

Estudante N - Dutra: "Sons de pássaros, vento balançando as árvores e etc.”;

Estudante P - Dutra: “Som da cachoeira, das folhas batendo umas nas outras por causa do vento”;

Estudante Q - Dutra: “Água descendo rio abaixo. Pássaro cantando”.

A percepção auditiva se revelou bastante apurada entre os estudantes. A luminosidade nos quatro pontos da trilha também foi percebida. Os estudantes apontaram o açude como de luminosidade intensa, o ponto da ETA CEDAE de luminosidade média a intensa, o ponto do Jequitibá-rosa com média luminosidade e o ponto da Pedra do G4 como de pouca luminosidade, condizendo com a realidade daqueles dias na trilha. Infere-se, com base nos dados, que o contato com os objetos de estudo, in loco, propiciou a percepção. A capacidade de percepção ambiental dos estudantes também foi observada para o microclima nos diferentes pontos da trilha. Tanto os 
alunos do CAIC quanto do Dutra apontaram o microclima agradável a quente no açude, na ETA CEDAE e no Jequitibá-rosa. Já na Pedra do G4 os estudantes citaram o microclima como agradável. Isso revela a capacidade de percepção ambiental dos estudantes ao longo da atividade na trilha.

Quanto à biodiversidade, os estudantes citaram na planilha uma variedade de seres vivos. Escreveram os nomes populares das plantas e animais que observaram no percurso da trilha, exemplos como: bicho-pau, cigarras e formigas, visto que encontraram um formigueiro, borboletas, libélulas, grilos, moscas, mosquitos, marimbondo, gafanhoto, joaninhas, cupim, lagarta, carrapato, aranha, gongolo, lagartos, besouros, calangos, pássaros, sabiás, canários, micos, cogumelos, flor, bromélias, bambu, samambaia, pé de jaca e o Jequitibá-rosa. Citaram, também, líquens, fungos e musgos. Antes da atividade na trilha, os alunos desconheciam o conceito de líquens, não associavam o cogumelo aos fungos e desconheciam musgo como um organismo vivo.

A partir das problematizações, no percurso da trilha, questões como os cogumelos e a relação dos fungos na ciclagem de nutrientes foram construídos. A simbiose dos líquens e as diversas outras interações entre os seres vivos como a interação das aranhas com o meio na localização da teia e com suas presas, as bromélias no alto das árvores como suporte para obter mais luz, umidade e nutrição foram construídos de maneira coletiva. Conforme Marandino et al. (2009) e Pinto e Camilo (2020) essas oportunidades do contato com objetos/ambientes/ experiências, em atividades de campo, podem proporcionar contatos particulares com o conhecimento. Além disso, expressões que envolvem os seres vivos e sua interação com o meio ambiente foram citados e abordados entre os estudantes e professores ao longo da atividade na trilha: Estudante D - CAIC: "Insetos= reproduzindo"; "Árvores= fazendo sombra"

Estudante F - CAIC: "Os pássaros cantando e os insetos nas árvores e as privacidades e as plantas”

Estudante G - CAIC: "É interessante pois eles se interagem entre eles e com a nossa presença eles agem diferente"

Estudante I - CAIC: “Todos são dependentes da natureza”

Estudante A - Dutra: "Aranha que enrolou uma cigarra para se alimentar"; "As formigas que estavam carregando folhas para se alimentar"

Estudante H - Dutra "A interação com as plantas, as árvores, o clima, os insetos e os animais"

Estudante S - Dutra: “As formigas carregando pequenos pedaços de folhas”

Embora a maioria dos alunos tivesse uma percepção, inicial, antropocêntrica e utilitarista do meio ambiente, a partir das problematizações e discussões foi possível uma mudança de paradigma. A importância da água para a manutenção da vida do ser humano e de outras espécies de seres vivos foi tratada. O meio ambiente passou a ser visto pelos estudantes como um conjunto de elementos vivos ou não vivos em um equilíbrio dinâmico, incluído o ser humano. Buscou-se ao longo das problematizações e diálogos desconstruir a concepção incorreta de que o meio ambiente deve servir ao homem. De acordo com Guimarães (2006), Reigota (2010), Loureiro (2012), Pinto e Camilo (2020) existe um processo histórico que gerou essa concepção incorreta de que o ser humano não faz parte da natureza.

O escoamento superficial e o desmatamento da vegetação foram abordados. Debates como os que ganham e os que perdem com o desmatamento foram realizados de maneira crítico-reflexiva com perguntas como: O que causa o desmatamento? Quais são as doenças causadas pelo desmatamento? 
Com base nas questões problematizadas e diálogos, observou-se que os alunos passaram a correlacionar a importância da Mata Atlântica para a manutenção de elementos importantes como a água, o clima, a biodiversidade e a interligação entre os mesmos, incluindo o ser humano neste sistema, conforme falas dos estudantes:

Estudante F - Dutra: "Eu notei que aqui o clima é mais agradável que na cidade”; "Então, o desmatamento pode causar a escassez da água!”

Estudante I - CAIC: “Somos todos dependentes da natureza”

\section{Estudante A - Dutra: "Somos seres de Mata Atlântica!”}

Aspectos da serrapilheira para a recomposição dos nutrientes, proteção do solo e várias outras funções no ecossistema foram refletidas e discutidas. Alguns exemplos de falas e registros pelos alunos na planilha diagnóstica são destacados a seguir: "Para ciclar nutrientes"; "Servindo como adubo", "Para proteger o solo ou cobrir o solo"; "Para as plantas se desenvolverem"; "Para manter o solo úmido"; "Atua coberta de folhas"; "Para proteger o solo"; "Para refrescar, regar"; "Como adubo"; "Para o crescimento de novas plantas".

Por meio dos registros na planilha foi possível observar, também, que os estudantes, mesmo sem se darem conta, trataram de conhecimentos mais abstratos como os ciclos biogeoquímicos. Com base nas reflexões e diálogos dos aspectos do solo e serrapilheira, observou-se maior facilidade dos alunos compreenderem conceitos básicos da ecologia como decomposição e ciclagem de nutrientes. Este conjunto de percepções e problematizações, na trilha, proporcionaram aos alunos perceberem "como no meio ambiente, morte e vida não existem uma sem a outra, elas se complementam no ciclo biológico constituindo uma unidade” (LOUREIRO, 2011 p. 21). O contato com os objetos de estudo na trilha do Jequitibá-rosa permitiu, também, o interesse pela descoberta e valorização de temas que muitas vezes é conceituado de maneira abstrata em sala de aula.

Por fim, antes das planilhas serem recolhidas, foi solicitado que os estudantes definissem a experiência na trilha com apenas uma palavra ou expressão, os alunos citaram: "Agradável; Alegria; Aventura; Beleza; Chuva de folhas; Descoberta; Felicidade; Gratidão; Interessante; Linda; Paz; Sossego; Tranquilidade; Descobridora; Importante; Inédita; Inovadora; Interessante; Maravilhosa; Natural; Nirvana; Novo; Vida; Sonho; Tranquila; Tranquilizadora; Um caminho sonoro".

Por esses registros e relatos, depreende-se que as atividades desenvolvidas na trilha ecológica do Jequitibá-rosa, além de favorecer a aprendizagem de conhecimentos científicos de maneira agradável e prazerosa, favoreceu a reflexão-crítica em uma perspectiva socioambiental.

\section{CONSIDERAÇÕES FINAIS}

O uso de espaços não formais como as trilhas para proporcionar o contato com objetos de estudos e vivenciar experiências, com o objetivo educacional, é oportuno, visto que nos aproxima da natureza, deixando os estudantes à vontade para “investigar' tudo que a curiosidade permitir. São espaços ótimos para a sociabilidade, para o "re" afloramento da afetividade com os demais seres vivos e com o planeta. Além disso, permite problematizar a lógica de consumo vigente na sociedade, a exploração do uso dos recursos naturais e as externalidades do processo de produção e consumo.

A pesquisa evidenciou que o uso da planilha de diagnóstico contribuiu para o levantamento da percepção ambiental dos alunos, ao longo do trajeto da trilha, acerca dos aspectos socioambientais observados, além de estimular a autonomia dos estudantes. Por meio da percepção ambiental foi possível conhecer os problemas socioambientais do cotidiano dos estudantes oportunizando problematizações e diálogos, que favoreceram, assim, uma melhor construção do conhecimento da temática ambiental. 
A percepção ambiental se revelou bastante apurada para diversos aspectos entre os estudantes. A pesquisa revelou que com o contato direto com os elementos do meio ambiente encontrados ao longo da trilha, houve a construção de conceitos novos e uma relação mais ampla dos diversos aspectos relacionados ao meio ambiente. Verificaram-se tanto no registro da planilha como nas primeiras problematizações, uma visão predominantemente antropocêntrica e utilitarista da natureza, essa concepção inicial foi modificada ao longo da ampliação das discussões favorecendo uma aprendizagem de maneira crítico-reflexiva.

Foi possível concluir que as atividades realizadas em espaço não formal, nesta pesquisa, contribuíram efetivamente para o processo de ensino aprendizagem de conteúdos de Ciências e Biologia e questões socioambientais. O contato proporcionado pela vivência na trilha do Jequitibá-rosa permitiu o interesse pela descoberta e valorização de temas que muitas vezes são abordados de maneira abstrata quando tratado apenas na sala de aula e sem o contato com o objeto de estudo.

\section{AGRADECIMENTO}

Este estudo teve auxílio financeiro provido pelo Comitê de Bacias Hidrográficas do rio Guandu/Agência de bacias - AGEVAP. Teve também auxílio do PIBIC/IC/UFRRJ.

\section{REFERÊNCIAS}

ACORDI. O.S.G.; PASA. M. C. Trilha ecológica pedagógica como estratégia de ensino-aprendizagem nas escolas do município de Apiacás, MT, Brasil. Biodiversidade, v.13, n. 1, p. 106 a 114, 2014.

ALVES, D. Sensopercepção em ações de Educação Ambiental. Brasília: MEC/INEPE, p.79. (Série documental, antecipações, n.7). 1995.

ALVES, S. C. V. Estado da arte dos estudos sobre percepção ambiental no brasil no período entre 2008 e 2015. Dissertação (Mestrado em Psicologia) - Instituto de Educação, Universidade Federal Rural do Rio de Janeiro, Rio de Janeiro, 2016.

BASTOS, F. Construtivismo e ensino de ciências. In: NARDI, R. (Org.). Questões atuais no ensino de ciências. São Paulo: Escrituras, 1998. p. 9-25.

DEL RIO, V.; OLIVEIRA, L. Percepção ambiental: a experiência brasileira. 2 ed. São Paulo: Studio Nobel, 1999.

DOLFLLUS, O. O Espaço Geográfico. 5a ed. Rio de Janeiro. Editora: Bertrand Brasil.1991.

FERREIRA-ALVIM, G. F.; PINTO, B. C. T. Fotografia e linguagem: um olhar sobre o meio ambiente de um grupo de estudantes do ensino fundamental. In: VIII Encontro Regional de Ensino de Biologia RJ/ES, 2017, Rio de Janeiro. VIII Erebio RJ/ES, 2017.

FREITAS, C. S. S.; LOPES, E. S.; PINTO, B. C. T. Trilhas ecológicas educativas em espaços não formais do Parque NaturalMunicipal do Curió - Paracambi, RJ. Revista da SBEnBio, v 9, p. 5797-5808, 2016.

FREITAS, C. S. S.; LOPES, E. S.; PINTO, B. C. T. Percepção ambiental: um olhar de estudantes da baixada do Rio de Janeiro sobre meio ambiente e problemas socioambientais do cotidiano. In: IX Encontro Pesquisa em Educação Ambiental, 2017, Juiz de Fora. IX EPEA Encontro Pesquisa em Educação Ambiental, 2017.

GIL-PÉREZ, D.; GUISASOLA, J.; MORENO, A.; CACHAPUZ, A.; PESSOA DE CARVALHO, A. M.; MARTÍNEZ TORREGROSA, J.; SALINAS, J.; VALDÉS, P.; GONZÁLEZ, E.; GENÉ DUCH, A.; DUMAS- 
CARRÉ, A.; TRICÁRICO, H.; GALLEGO, R. Defending constructivism in Science education. Science \&Education, v. 12, p. 557-571, 2002.

GUIMARÃES, M. Caminhos da educação ambiental da forma à ação. $4^{\circ}$ ed. São Paulo: Papirus. 2006. 112 p.

LECHNER, L. Planejamento, implantação e manejo de trilhas em unidades de conservação. Cadernos de Conservação. Fundação O Boticário de Proteção à Natureza, v. 3, p. 1-123. 2006.

LOUREIRO, C. F. Trajetória e fundamentos da Educação Ambiental. São Paulo: Cortez. 2012. 150 p.

LOUREIRO, C. F.; TORRES, J. R. Educação ambiental: dialogando com Paulo Freire. São Paulo: Cortez, 2014.

LOUREiro, C. F, B.; LAYRARGUES, P. P.; CASTRO, R. S. (Orgs.). Pensamento Complexo, Dialética e Educação Ambiental. São Paulo: Cortez, 2011.

MARANDINO, M.; SELLES, S. E.; FERREIRA, M. S. Ensino de Biologia: histórias e práticas em diferentes espaços educativos. São Paulo: Cortez, 2009.

MARCONI, M. A.; LAKATOS, E. M. Metodologia científica. São Paulo: Atlas, 2010.

MARIN, A. A. Pesquisa em educação ambiental e percepção ambiental. Universidade Federal do Paraná. Pesquisa em Educação Ambiental, v. 3, p. 203-222, 2008.

MARQUES, V.; SATRIANO, C. R; GARCIA, M. G. M. Uso de trilha na aprendizagem significativa interdisciplinar. In: Marques, V; Pereira-Filho, G. H. (Org.). Mergulho: uma nova ferramenta educacional. 1ed. Seropédica: EDUR, v. 1, p. 50-62, 2013.

MENGHINI, F. B. As trilhas interpretativas como recurso pedagógico: caminhos traçados para a Educação Ambiental. Dissertação, Itajaí, SC. 2005. 103 p.

OLIVEIRA, L. Percepção Ambiental. Revista Geografia e Pesquisa, v.6, n.2, 2009.

PIN, J.R.O. As trilhas ecológicas como espaço educativo para o ensino: um estudo sobre as compreensões de professores de Ciências da educação básica. Tese (doutorado)- Centro Federal de Educação Tecnológica Celso Suckow da Fonseca, CEFET, RJ - Programa de Pós-graduação em Ciência, Tecnologia e Educação. 2019.

PIN, J; CAMPOS, C. R. P. Um olhar interdisciplinar sobre as trilhas ecológicas. Tecnologia \& Cultura, v. 16, p. 26-34, 2014.

PINTO, B. C. T.; BORGES, J. L. C. Uma atividade de educação ambiental em espaço não formal: potencialidades do uso de bacias hidrográficas. Revista Tempos e Espaços em Educação, v. 8, p. 109-124, 2015.

PINTO, B. C. T.; CAMILO, G. S. Atividade prática de educação ambiental em espaço não formal: aspectos da bacia hidrográfica como tema gerador. Ambiente \& Educação, v. 25, p. 536-558, 2020.

REIGOTA, M. Meio Ambiente e representação social. 8. ed. São Paulo: Cortez, 2010.

ROCHA M. B.; HENRIQUE. R. L.; QUITÁ. C.; SILVEIRA. L. F.; VASCONCELLOS. V. Estudos sobre trilhas: uma análise de tendências em eventos de Ensino de Ciências e Educação Ambiental. Acta Scientia e Canoas, v.18, n.2 p.517-530, 2016.

ROMEIRO, A. R. Economia ou economia política da sustentabilidade. In: MAY, P. H (org.). Economia do Meio Ambiente. Teoria e Prática. 2 ed. Rio de Janeiro: Elsevier, 2010. 379 p.

VYGOTSKY, L. S. A construção do pensamento e da linguagem. São Paulo: Martins Fontes, 2001. 496 p. 